Check for updates

Cite this: RSC Adv., 2017, 7, 21114

Received 9th December 2016

Accepted 6th April 2017

DOI: $10.1039 / c 6 r a 27979 a$

rsc.li/rsc-advances

\title{
Efficacy of ionic liquids on the growth and simultaneous xylanase production by Sporotrichum thermophile: membrane integrity, composition and morphological investigation
}

\begin{abstract}
Ayesha Sadaf (iD) and S. K. Khare (iD *
Ionic liquids (ILs) are emerging as promising solvent systems for carrying out various biochemical reactions. The application of whole microbial cells for carrying out catalysis in the presence of ILs is gaining interest due to the advantages of being cost effective and providing a natural environment for enzymes. Present study elucidates the tolerance of a thermophilic fungus, $S$. thermophile, towards various hydrophilic imidazolium based ILs. [EMIM][OAc], [BMIM][MeSO $\left.{ }_{4}\right]$ and [BMIM][Otf] were found to be compatible and

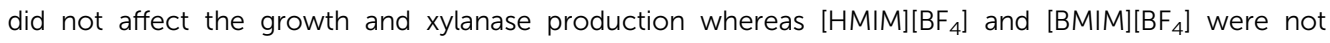
compatible and inhibited the growth drastically. The impact of two types of the ILs systems, compatible

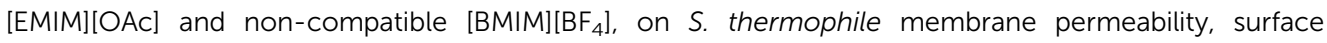
morphology, membrane characteristics and fatty acid composition were studied by SEM, TEM, AFM and FAME analysis. [EMIM][OAc] was tolerated by $S$. thermophile upto $4.0 \%(\mathrm{v} / \mathrm{v})$ concentrations and the cellular response in this particular IL was comparable with that of a control. In order to explore the feasibility of using whole cells of $S$. thermophile in place of its crude xylanase, a study was conducted for in situ pre-treatment and saccharification of [EMIM][OAc] treated wheat straw and a high amount of reducing sugars were released as compared to controls. IL stable cells can thus be utilised for simultaneous pre-treatment and saccharification.
\end{abstract}

\section{Introduction}

The concerns about exhaustion of fossil fuel reserves and the environmental pollution caused by their use have resulted in increasing efforts towards generating energy from other replenishable forms. ${ }^{1,2}$ Therefore, the energy derived from lignocellulosic biomass has garnered attention over the years due to its abundant availability. Various studies have been reported on the utilisation of lignocellulosic biomass for the generation of second generation biofuels. ${ }^{3,4}$ However due to the recalcitrant nature of lignocellulosic biomass, its pre-treatment using different processes becomes necessary. One key aim here is to separate the lignin layer. The pre-treatment methods are also used for reducing the crystallinity of the lignocellulosic biomass. These are steam explosion, ammonia fiber expansion (AFEX), ozonolysis, liquid hot water treatment, acid and alkali pre-treatment and (more recently) the use of room temperature ionic liquids. ${ }^{5-7}$

Room temperature ionic liquids (ILs) are salts consisting of an anion and a cation and possess some remarkable properties

Enzyme and Microbial Biochemistry Laboratory, Department of Chemistry, Indian Institute of Technology, Hauz Khas, New Delhi 110016, India. E-mail: skhare@ rocketmail.com; skkhare@chemistry.iitd.ac.in; Fax: +91 112658 1102; Tel: +91 11 26596533 like non-volatility, non-flammability, high temperature stability and good solvating ability. ${ }^{\mathbf{8} 9}$ Due to these unique properties, ILs find their way in numerous industrial applications which use these as solvents or reaction media. ${ }^{\mathbf{1 0}-12}$ However the use of ILs in microbe based processes poses some challenges. ${ }^{13,14}$ Therefore, the search or screening for microorganisms compatible with ILs is an active area of research. ${ }^{15,16}$

Imidazolium based ILs are one of the most commonly used ILs systems for industrial applications. Some commonly used imidazolium based ILs are [EMIM] [OAc], [BMIM] $\left[\mathrm{BF}_{4}\right],[\mathrm{BMIM}]$ $\left[\mathrm{MeSO}_{4}\right]$ and $[\mathrm{BMIM}][\mathrm{Cl}]$. Many previous studies have reported the toxicity of imidazolium ILs towards microorganisms. ${ }^{\mathbf{1 4 , 1 7}}$ The knowledge of interaction of ILs with bacteria or fungus is limiting because of fewer studies available on behaviour of bacterial cells in the presence of ILs. ${ }^{18,19}$ Therefore, understanding the effect of ILs on microorganisms producing relevant enzymes is extremely important and needs to be further studied for application of ILs in whole cell biocatalysis.

We have previously reported the stability of xylanase from a thermophilic mould Sporotrichum thermophile in various imidazolium ILs. ${ }^{20}$ In the present work the behaviour of $S$. thermophile in different hydrophilic imidazolium based ILs was investigated. Initially, five different types of imidazolium ILs namely [EMIM] [OAc], [BMIM] $\left[\mathrm{MeSO}_{4}\right]$, [BMIM] $[\mathrm{Otf}],[\mathrm{BMIM}]$ 
$\left[\mathrm{BF}_{4}\right]$ and $[\mathrm{HMIM}]\left[\mathrm{BF}_{4}\right]$ were screened for the growth and simultaneous xylanase production from thermophilic mould. Those ILs which were found conducive to the growth of $S$. thermophile and xylanase production were further studied.

To explore the effect of ILs on morphological, cytoplasmic and membrane characteristics of S. thermophile, SEM (Scanning Electron Microscopy), TEM (Transmission Electron Microscopy), AFM (Atomic Force Microscopy) and FAME (Fatty Acid Methyl Ester) analysis were carried out.

The end application was to examine the feasibility of using whole cells of $S$. thermophile in place of its xylanase for saccharification. This approach thus combines pre-treatment as well as biocatalysis in ILs.

\section{Experimental}

\section{Chemicals}

1-Butyl-3-methylimidazolium tetrafluoroborate $[\mathrm{BMIM}]\left[\mathrm{BF}_{4}\right], 1$ butyl-3-methylimidazolium trifluoromethanesulfonate [BMIM] [Otf], 1-hexyl 3-methyl imidazolium tertrafluoroborate [HMIM] $\left[\mathrm{BF}_{4}\right]$, 1-ethyl-3-methylimidazolium-acetate [EMIM] [OAc] and 1butyl-3-methylimidazolium methanesulfonate $[\mathrm{BMIM}]\left[\mathrm{MeSO}_{4}\right]$ were purchased from Sigma-Aldrich (St. Louis, MO, USA). Beechwood xylan was purchased from Hi-Media (Mumbai, India). All other chemicals used were of analytical grade.

\section{Microorganism and growth conditions}

The xylanase producing thermophilic mould Sporotrichum thermophile was generously provided by Prof. T. Satyanarayana (Department of Microbiology, Delhi University, South Campus, New Delhi, India). The strain was maintained on potato dextrose agar (PDA) slants (pH 7.0) at $4{ }^{\circ} \mathrm{C}$ and sub-cultured at 15 days interval. Inoculum was prepared by scraping $10 \mathrm{mg}$ weight of fresh mycelium from PDA slants and suspending into $5.0 \mathrm{~mL}$ of sterile saline solution. Emerson's medium (soluble starch 15, yeast extract 4.0, $\mathrm{K}_{2} \mathrm{HPO}_{4} 1.5, \mathrm{MgSO}_{4}, 0.5 \mathrm{in} \mathrm{L}^{-1}, \mathrm{pH}$ 9.0) was inoculated with $2.0 \%(\mathrm{v} / \mathrm{v})$ inoculum of $48 \mathrm{~h}$ grown mycelium and incubated at $40{ }^{\circ} \mathrm{C}$ with constant shaking at $120 \mathrm{rpm}$.

\section{S. thermophile growth and simultaneous xylanase production in the presence of different imidazolium based ILS}

To determine the effect of different ILs on S. thermophile growth and xylanase production, Erlenmeyer flasks containing $20.0 \mathrm{~mL}$ of sterile Emerson's medium with $0.5 \%(\mathrm{v} / \mathrm{v})$ of various ILs taken were inoculated with $2.0 \%(\mathrm{v} / \mathrm{v})$ fresh inoculum. The flasks were incubated at $40{ }^{\circ} \mathrm{C}$ in an orbital shaker at $100 \mathrm{rpm}$ and harvested at regular time intervals. Fungus growth rate was determined by measuring the mycelial biomass content and the optical density (O.D) of the culture media at $600 \mathrm{~nm}$. The mycelium was scattered before the detection. Increase in O.D was taken as the indication of growth at different time intervals. The biomass was determined as mycelial dry weight $\left(\mathrm{g} \mathrm{L}^{-1}\right)$ after filtration through membrane filter with pore size $0.22 \mu \mathrm{m}$ (Millipore, Ireland) and subsequent washing with distilled water. The samples were dried and weighed. A part of harvested sample was centrifuged at $12000 \mathrm{rpm}$ for $10 \mathrm{~min}$ at $4{ }^{\circ} \mathrm{C}$ and the clear cell free supernatant was used for xylanase assay.

To increase the tolerance of $S$. thermophile in compatible ILS systems, first the culture was grown at lower concentration of a particular IL, the resultant spores which appeared in the presence of this IL were maintained on PDA plates. These IL adapted spores were then used to inoculate next run of $S$. thermophile culture with increasing concentration of the respective ILs. This methodology was adapted so that only those spores which have become tolerable to ILs can grow on PDA plates. All the growth curves are represented by plotting the natural logarithm of the fungal biomass against different time intervals.

\section{Xylanase assay}

Briefly, $0.5 \mathrm{~mL}$ of a suitable diluted enzyme extract was mixed with $0.5 \mathrm{~mL}$ of beechwood xylan $(1 \% \mathrm{w} / \mathrm{v}$ in $0.05 \mathrm{M}$ sodium phosphate buffer, $\mathrm{pH}$ 7.0). The reaction mixture was incubated at $50{ }^{\circ} \mathrm{C}$ for $15 \mathrm{~min}$. The reducing sugars generated as reaction product were quantified by dinitrosalicylic acid (DNS) method. ${ }^{21}$ One unit of enzyme activity is defined as the amount of enzyme required to produce $1 \mu \mathrm{mol}$ of reducing sugar (xylose) per minute.

\section{MTT assay}

MTT (3-[4,5-dimethylthiazol-2-yl]-2,5-diphenyltetrazolium bromide; thiazolyl blue) assay was done as described by Freimoser et al. (1999) $)^{22}$ briefly, MTT stock solution $\left(5 \mathrm{mg} \mathrm{mL}^{-1}\right)$ was added to the cultures growing in the presence or absence of ILs at a final concentration of $0.5 \mathrm{mg} \mathrm{mL} \mathrm{m}^{-1}$. The mixture was incubated for $4 \mathrm{~h}$ on a shaker $\left(120 \mathrm{rpm}\right.$ at $\left.20^{\circ} \mathrm{C}\right)$. After the incubation period, the cells were pelleted by centrifugation (10 $000 \mathrm{rpm}$ at $20{ }^{\circ} \mathrm{C}$ for $15 \mathrm{~min}$ ) and the medium was discarded. The converted dye was solubilised by adding acidic isopropanol $(0.04 \mathrm{M} \mathrm{HCl}$ in absolute isopropanol) and the absorbance of the coloured product was read at $570 \mathrm{~nm}$ against a blank (consisting MTT reagent and acidified isopropanol).

\section{Membrane permeability studies}

The cell membrane permeability was measured as the release of proteins and nucleic acids during the growth of $S$. thermophile in the presence and absence of ILs. Briefly $20 \mathrm{~mL}$ of Emerson's medium containing different concentrations $(2.0 \%$ and $4.0 \%, \mathrm{v} /$ v) of ILs both compatible and non-compatible type [EMIM][OAc] and $[\mathrm{BMIM}]\left[\mathrm{BF}_{4}\right]$ were inoculated with $2.0 \%(\mathrm{v} / \mathrm{v})$ inoculum size of adapted S. thermophile cells and incubated for $72 \mathrm{~h}$ at $40{ }^{\circ} \mathrm{C}$ with shaking at $120 \mathrm{rpm}$. Samples were withdrawn at regular intervals and centrifuged (10 $000 \mathrm{rpm}$ for $15 \mathrm{~min}$ ). Absorbance at $260 \mathrm{~nm}$ and $280 \mathrm{~nm}$ of the clear supernatant was recorded for the estimation of DNA and proteins respectively.

All the experiments were done in triplicates and the variation was within $\pm 5 \%$.

\section{Scanning electron microscopy (SEM) and transmission electron microscopy (TEM)}

The surface morphological changes as well as the ILs effect on membrane was characterised by using (SEM) and (TEM). 
$S$. thermophile adapted in ILs was grown in the absence and presence of $2.0 \%(\mathrm{v} / \mathrm{v})$ of the two selected ILs, [EMIM] [OAc] and $[\mathrm{BMIM}]\left[\mathrm{BF}_{4}\right]$. The mycelium was harvested at the log phase of growth and processed for SEM (ZEISS EVO Series Scanning Electron Microscope Model EVO 50, Germany) by the method of Gupta et al. ${ }^{23}$ and TEM (Morgagni 268D Fei Electron Optics, AIIMS facility, New Delhi, India) as per the procedure of David et $a .^{24}$

\section{Atomic force microscopy (AFM)}

The surface morphology of spores in response to ILs was further elucidated by AFM. Briefly $S$. thermophile adapted in ILs was grown in the absence and presence of $2.0 \%(\mathrm{v} / \mathrm{v})$ of [EMIM] [OAc] and $[\mathrm{BMIM}]\left[\mathrm{BF}_{4}\right]$ and processed further for imaging by AFM (Bruker INNOVAA2-SYS, Massachusetts, USA) in contact mode at a scan rate of $2.0 \mathrm{~Hz}^{23}$

\section{Fatty acid methyl ester (FAME) analysis}

The $S$. thermophile adapted in ILs was grown in the absence and presence of $2.0 \%(\mathrm{v} / \mathrm{v})$ of [EMIM] [OAc] and [BMIM] $\left[\mathrm{BF}_{4}\right]$. The mycelium was harvested at the log phase of growth and lyophilised. The lyophilised mycelia were ground to a powder form and further processed for fatty acid methyl ester analysis. ${ }^{25}$ The extracts obtained were identified using GC-MS (ModelAgilent Technologies, Wilmington, DE, USA) using helium as the carrier gas. The column temperature was initially maintained at $80{ }^{\circ} \mathrm{C}$ for $1.0 \mathrm{~min}$ then increased to $250{ }^{\circ} \mathrm{C}$ for $5 \mathrm{~min}$ at the rate of $8{ }^{\circ} \mathrm{C} \mathrm{min}^{-1}$ followed by final increase to $290{ }^{\circ} \mathrm{C}$ for $6.0 \mathrm{~min}$ at the rate of $10^{\circ} \mathrm{C} \mathrm{min}^{-1}$. The fatty acid were identified using standard in built mass spectra by NIST (National Institute of Standards and Technology, Maryland, USA).

\section{Whole cell biocatalysis by using IL adapted $S$. thermophile cells}

The IL adapted culture of $S$. thermophile was grown in the presence of $4.0 \%(\mathrm{v} / \mathrm{v})$ [EMIM] [OAc] and the mycelium was harvested at the log phase of growth. The resultant adapted culture containing xylanase activity $\left(25 \mathrm{U} \mathrm{mL}^{-1}\right)$, was added to IL pre-treated wheat straw $\left(0.5 \mathrm{~g}\right.$ in $1.0 \mathrm{~mL}$ [EMIM] [OAc], $120^{\circ} \mathrm{C}$ for $3 \mathrm{~h}$ ) at $33 \%(\mathrm{w} / \mathrm{w})$ biomass loading and the saccharification was performed with continuous shaking at $40{ }^{\circ} \mathrm{C}$ for $48 \mathrm{~h}$. To follow the course of reaction, samples were periodically withdrawn, centrifuged to obtain a clear supernatant and the resultant reducing sugars were estimated by DNS method. In addition to the above experiment three controls were also run simultaneously.

In the first control, IL was replaced by $0.05 \mathrm{M}$ phosphate buffer $\mathrm{pH} 7.0$ for the pre-treatment of wheat straw under the above mentioned conditions and the saccharification was performed with adapted culture containing xylanase activity of $25 \mathrm{U}$ $\mathrm{mL}^{-1}$, in the second control, IL was used to pre-treat wheat straw under the above mentioned conditions followed by hydrolysis in the absence of cells. In the third control, IL pretreated wheat straw under the above mentioned conditions was hydrolysed in the presence of non-adapted $S$. thermophile cells containing xylanase activity of $55 \mathrm{U} \mathrm{mL}^{-1}$.

\section{Results and discussion}

\section{Stability of $S$. thermophile for growth and simultaneous xylanase production in different ILs}

Five different imidazolium based ILs were taken at a concentration of $0.5 \%(\mathrm{v} / \mathrm{v})$ and the growth characteristics as well as the simultaneous xylanase production were observed over a definite period of time with respect to a control wherein these processes were observed in the absence of any ILs. As compared to the control, the fungus was able to grow in the presence of [BMIM] [Otf], [EMIM] $[\mathrm{OAc}]$ and [BMIM] $\left[\mathrm{MeSO}_{4}\right]$ with $\log$ biomass values of $2.5,2.4$ and 2.3 (O. $\mathrm{D}_{600}=3.8,3.4$ and 3.3 respectively) (Fig. 1a). Since all the ILs taken were composed of a common imidazolium cation the effects were mainly due to the anion moiety. The two tetrafluoroborate anion containing ILs viz. $[\mathrm{BMIM}]\left[\mathrm{BF}_{4}\right]$ and $[\mathrm{HMIM}]\left[\mathrm{BF}_{4}\right]$ showed maximum growth inhibition. The reason behind the deleterious effect may be possibly due to the chaotropic nature of $\left[\mathrm{BF}_{4}{ }^{-}\right]$anion in solutions. Chaotropic ions like $\left[\mathrm{BF}_{4}{ }^{-}\right]$exhibit weaker interactions with the water molecules and lead to their destructuring. ${ }^{26}$ These type of ions are also termed as "structure breakers" and have been reported to negatively impact membranes and proteins. The inhibitory effect of $\left[\mathrm{BF}_{4}{ }^{-}\right]$on microorganisms as well enzymes have been documented previously. ${ }^{27-31}$

The simultaneous xylanase production was found to be growth dependent, and reached its maximum after $48 \mathrm{~h}$ of growth in the presence of ILs as compared to $24 \mathrm{~h}$ in the absence of any ILs (Fig. 1b). The xylanase activities (50, 48 and $\left.30 \mathrm{U} \mathrm{mL}^{-1}\right)$ as compared to control $\left(65 \mathrm{U} \mathrm{mL}^{-1}\right)$ were found in the presence of [BMIM] $[\mathrm{Otf}],[\mathrm{BMIM}]\left[\mathrm{MeSO}_{4}\right]$ and [EMIM][OAc] respectively. The anions, $\left[\mathrm{OAc}^{-}\right],\left[\mathrm{Otf}^{-}\right]$and $\left[\mathrm{MeSO}_{4}{ }^{-}\right]$help in the interactions with water molecules and enable an ordered structure. These anions of the ILs are also called as "structure makers" or kosmotropic ions and have been reported to stabilise many proteins and enzymes. ${ }^{32-34}$ This might be the possible reason for the compatibility of $S$. thermophile in them.

\section{S. thermophile growth and xylanase production by $0.5 \%(\mathrm{v} / \mathrm{v})$ adapted cells of [EMIM][OAc], [BMIM] $\left[\mathrm{MeSO}_{4}\right]$ and [BMIM] [Otf]}

S. thermophile culture which was earlier adapted in $0.5 \%(\mathrm{v} / \mathrm{v})$ of [EMIM][OAc], [BMIM][ $\left.\mathrm{MeSO}_{4}\right]$ and [BMIM][Otf] could also grow well in $1 \%(\mathrm{v} / \mathrm{v})$ concentration of each these ILs. The growth profiles in general showed a variation when compared with the growth profiles in the absence of any IL. As seen in Fig. 2a and b, the typical profile of the growth curve and xylanase activity underwent significant changes in the presence of ILs as compared to that of control (in absence of ILs). These changes can be summarised as follows:

(i) There were no significant changes in the log phase but the slope was much lower in the ILs presence indicating a reduction in specific growth rate. The ILs might have possibly created some stress conditions allowing the cells to multiply but with less efficiency while simultaneously producing xylanase.

(ii) By and large the stationary phase disappeared in ILs presence followed by a pronounced and sharp decline phase. 


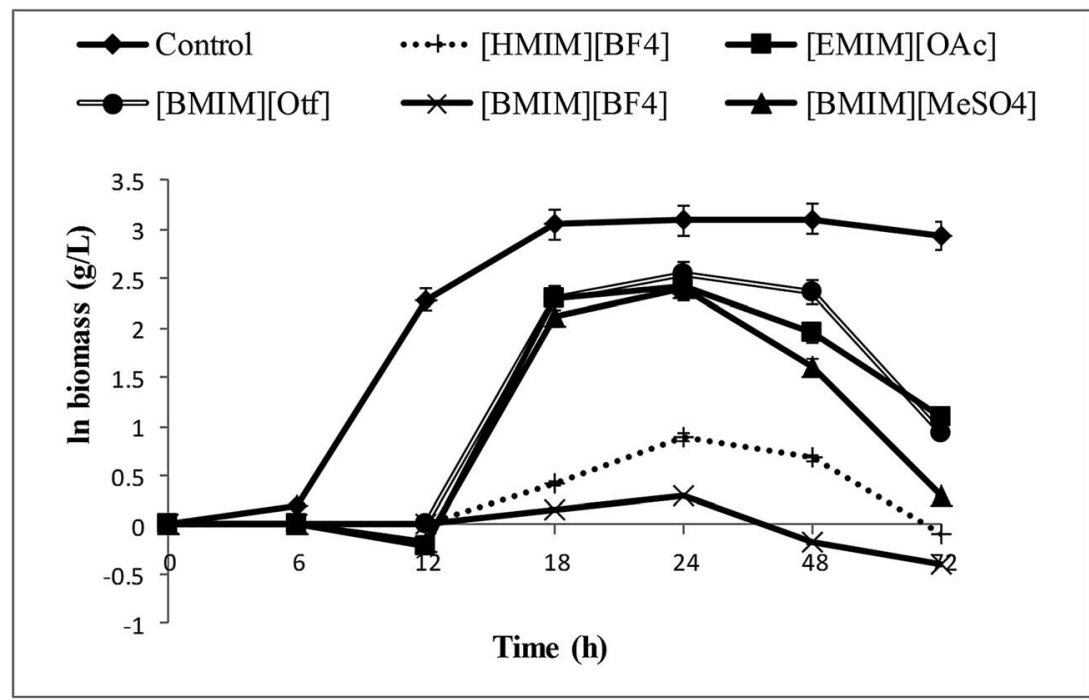

$1 \mathrm{a}$

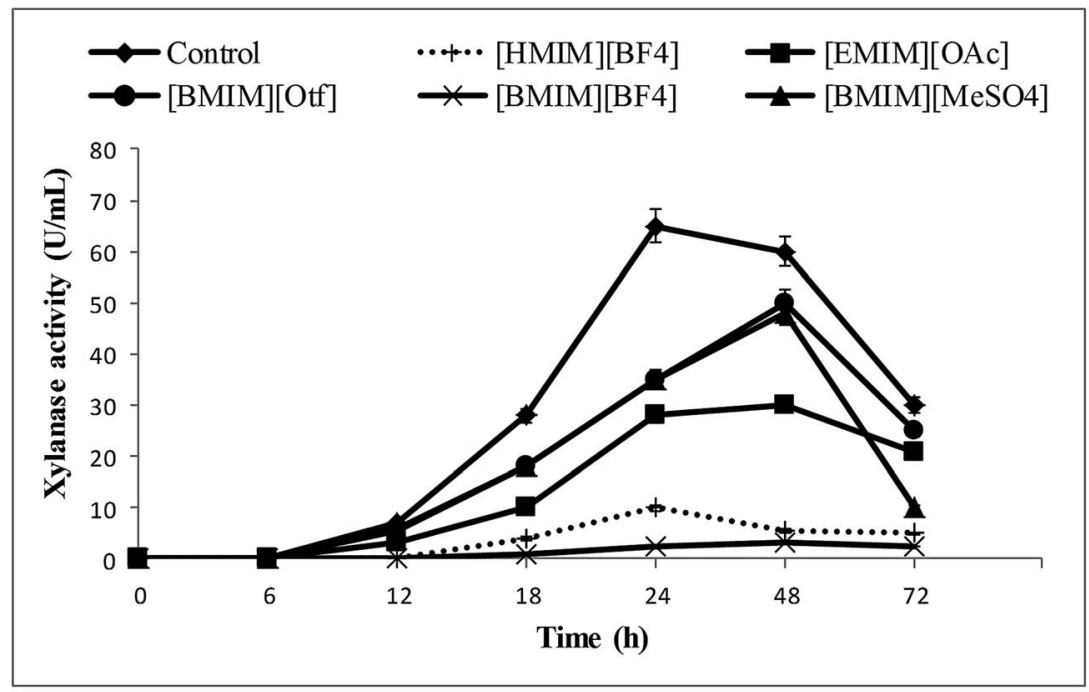

$1 \mathrm{~b}$

Fig. 1 Sporotrichum thermophile growth and simultaneous xylanase production in the presence of various imidazolium based ILs. S. thermophile was inoculated in Emerson's medium containing $0.5 \%(\mathrm{v} / \mathrm{v})$ of different imidazolium based ILs for $72 \mathrm{~h}$ at $40{ }^{\circ} \mathrm{C}$. (a) Growth of $\mathrm{S}$. thermophile and (b) xylanase production.

The xylanase activity curve was growth dependent and followed a similar trend.

The above features are typical of the cellular growth under solvent and osmotic stresses. ${ }^{35,36}$ Out of above mentioned ILs, [EMIM] [OAc], [BMIM] $\left[\mathrm{MeSO}_{4}\right]$ were selected for further adaptability studies since these are the commonly used ILs in biomass saccharification. ${ }^{3,37}$

\section{S. thermophile growth and xylanase production by $1.0 \%(\mathrm{v} / \mathrm{v})$ [EMIM] $[\mathrm{OAc}]$ and $[\mathrm{BMIM}]\left[\mathrm{MeSO}_{4}\right]$ adapted cells}

$S$. thermophile culture adapted previously in 1\% (v/v) [EMIM] [OAc] and [BMIM] $\left[\mathrm{MeSO}_{4}\right]$ was further grown in the presence of higher concentrations of the respective ILs. The growth and xylanase activity profile of adapted $S$. thermophile in Fig. 2c and d shows that [EMIM] [OAc] could be tolerated upto $4 \%(\mathrm{v} / \mathrm{v})$ concentration with $\log$ biomass value of $2.2\left(\right.$ O. $\left._{600}=2.8\right)$ and xylanase activity of $17 \mathrm{U} \mathrm{mL}^{-1}$ at $24 \mathrm{~h}$.

The second IL, [BMIM] $\left[\mathrm{MeSO}_{4}\right]$ was found to be tolerated upto $2 \%(\mathrm{v} / \mathrm{v})$ concentration with $\log$ biomass value of $2.0\left(\mathrm{O}_{\mathrm{D}} \mathrm{D}_{600}=\right.$ 2.4) and xylanase activity of $20 \mathrm{U} \mathrm{mL}^{-1}$ at $24 \mathrm{~h}$ (Fig. 2e and f).

The above studies thus concluded that $S$. thermophile was better adapted in [EMIM] [OAc] than in [BMIM] $\left[\mathrm{MeSO}_{4}\right]$.

\section{Viability studies by MTT assay in the presence of compatible} ILS

The cell viability of $S$. thermophile in ILs was quantified by performing MTT assay in the presence and absence of ILs. The adapted cells of $S$. thermophile were grown at varying 


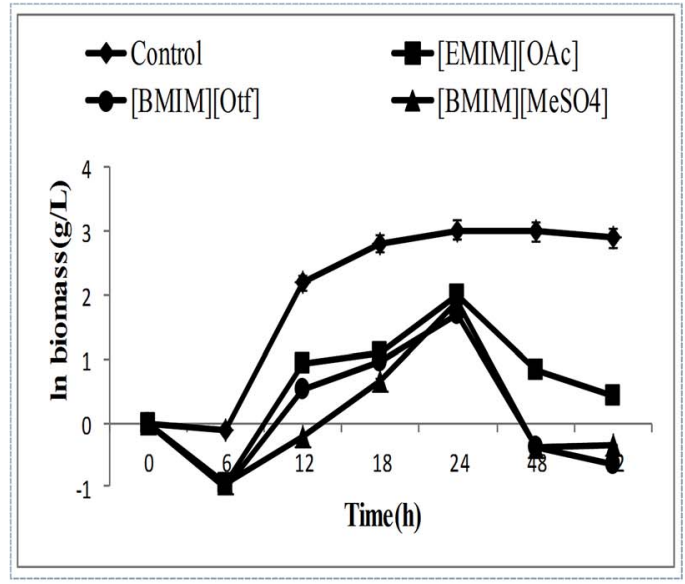

$2 \mathrm{a}$

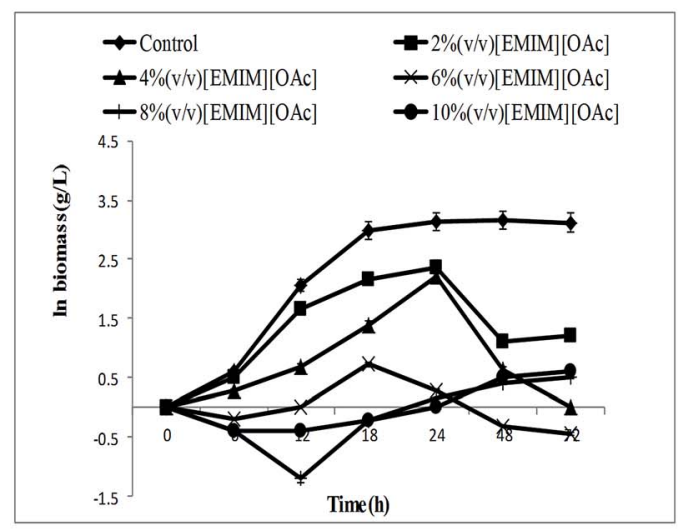

$2 \mathrm{c}$

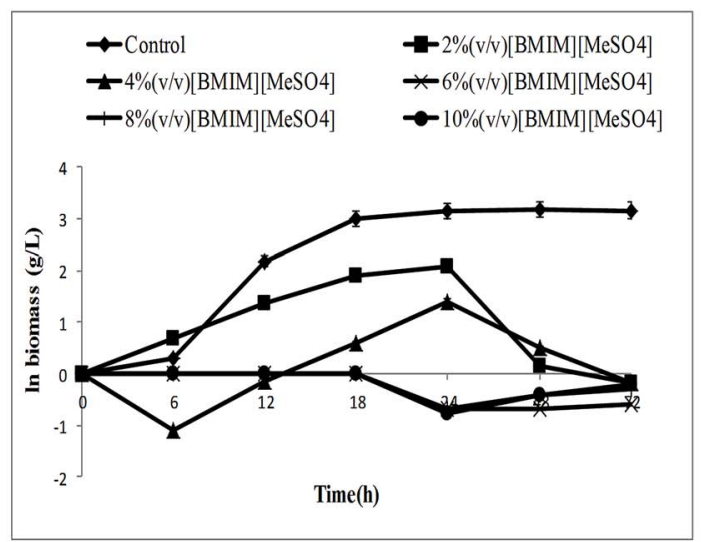

$2 \mathrm{e}$

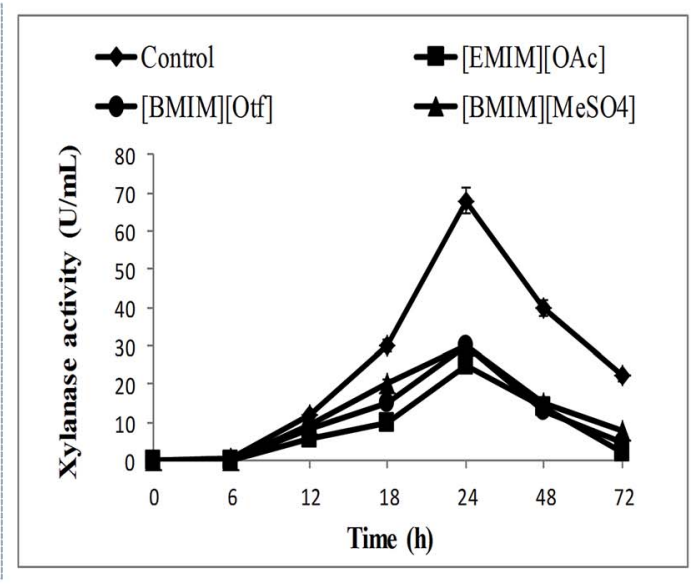

$2 b$

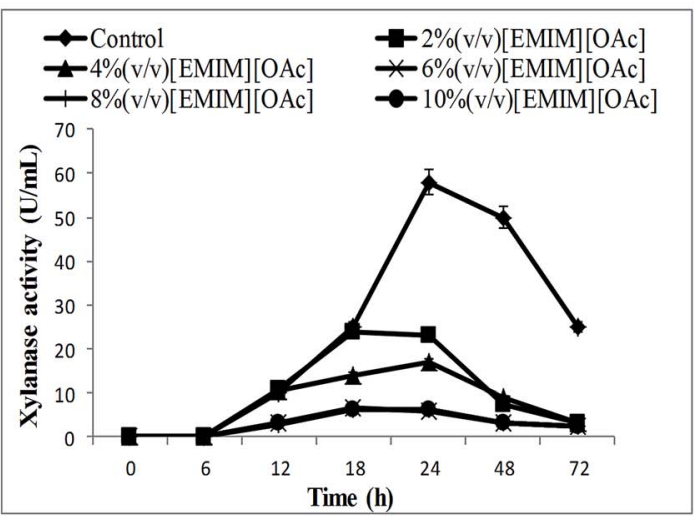

$2 d$

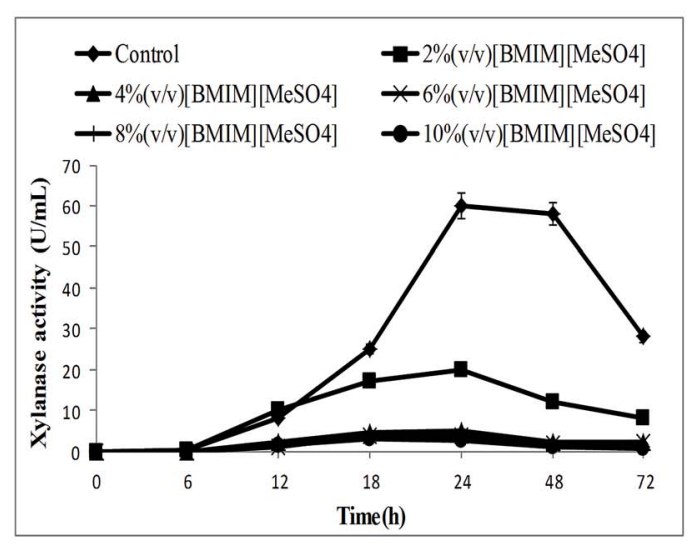

$2 \mathrm{f}$

Fig. 2 S. thermophile adaptation in ILs. S. thermophile which was earlier grown in $0.5 \%(\mathrm{v} / \mathrm{v})$ of various imidazolium based ILs was further inoculated in Emerson's medium containing $1 \%(\mathrm{v} / \mathrm{v})$ of the respective IL for $72 \mathrm{~h}$ at $40{ }^{\circ} \mathrm{C}$. (a) S. thermophile growth and (b) xylanase production in presence of ILs. S. thermophile culture adapted in $1 \%(\mathrm{v} / \mathrm{v})$ of [EMIM] [OAc] and [BMIM] $\left[\mathrm{MeSO}_{4}\right]$ were inoculated at higher concentrations $(2-10 \%$ $\mathrm{v} / \mathrm{v}$ ) of the two selected ILs (c) S. thermophile growth and (d) simultaneous xylanase production in the presence of [EMIM][OAc] (e) S. thermophile growth and (f) simultaneous xylanase production in the presence of [BMIM][MeSO 4$]$.

concentrations of compatible ILs ([EMIM][OAc] and [BMIM] $\left[\mathrm{MeSO}_{4}\right]$ ), harvested after $24 \mathrm{~h}$ and subjected to MTT assay as described in the materials and methods section. Since MTT assay is based on the activity of malate dehydrogenase enzyme which transforms the tetrazolium to a violet formazan, the absorbance due to this coloured product indicates a significant metabolic activity in the live cells. In the study conducted, malate dehydrogenase activity was comparable with respect to control at 2.0 and $4.0 \%(\mathrm{v} / \mathrm{v})$ concentration of [EMIM] [OAc] and at $2 \%(\mathrm{v} / \mathrm{v})$ concentration of $[\mathrm{BMIM}]\left[\mathrm{MeSO}_{4}\right]$ indicating rapid 
division of the fungal cells even in presence of ILs (Fig. 3). Hence the above studies validate the compatible nature of $[\mathrm{EMIM}][\mathrm{OAc}]$ and $[\mathrm{BMIM}]\left[\mathrm{MeSO}_{4}\right]$ towards $S$. thermophile growth and xylanase production. The adapted cells of $S$. thermophile were comparatively more viable in [EMIM][OAc] than in the presence of $[\mathrm{BMIM}]\left[\mathrm{MeSO}_{4}\right]$.

\section{Membrane integrity studies}

The release of nucleic acids and proteins if any during the growth of $S$. thermophile in the presence of two contrasting ILs i.e. $[\mathrm{EMIM}][\mathrm{OAc}]$ and $[\mathrm{BMIM}]\left[\mathrm{BF}_{4}\right]$ was recorded as a function of time to check whether the ILs affect the membrane or not. The cell membrane permeability was found to be altered in the presence of different concentrations of ILs. Fig. 4 shows the result of cell membrane permeability in the presence 2.0 and $4.0 \%(\mathrm{v} / \mathrm{v})$ of [EMIM] $[\mathrm{OAc}]$ and $[\mathrm{BMIM}]\left[\mathrm{BF}_{4}\right]$ respectively. The effect of ILs on membrane permeability can be explained by the fact that they interact with the charged part of membrane phospholipids/lipoproteins thereby altering its structure which leads to enhanced permeability. ${ }^{38,39}$ Similar observations have been previously reported by Yang et al., (2014) ${ }^{40}$ and Shen et al., (2016). ${ }^{19}$ However, in the present study it was seen that no nucleic acid was released during ILs exposure, but proteins were seen to be discharged in the medium along with growth. This implies that the cell membrane was ruptured to a larger extent whereas the nuclear membrane remained intact. The ratio of protein release with growth was plotted against different time intervals. The results clearly showed that as the time increased, the levels of protein release also increased indicating the enhanced membrane permeability. The effect was more pronounced in case of $[\mathrm{BMIM}]\left[\mathrm{BF}_{4}\right]$ than in the presence of [EMIM][OAc].

\section{SEM, TEM and AFM}

The morphological characterisation of $S$. thermophile mycelium in the presence of [EMIM] [OAc] and [BMIM] $\left[\mathrm{BF}_{4}\right]$ was observed by SEM (Fig. 5). In the absence of any ILs, the morphology of the

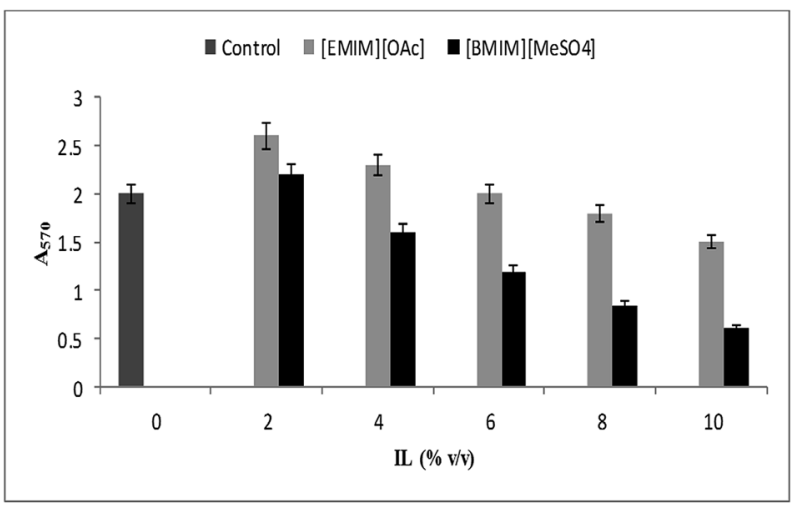

Fig. 3 Viability of adapted S. thermophile in the presence of different concentrations of ILs. The S. thermophile adapted cells were grown in Emerson's medium containing varying concentrations of compatible ILs ([EMIM][OAC] and [BMIM][MeSO 4$]$ ), harvested after $24 \mathrm{~h}$ and subjected to MTT assay as described in the Experimental section.

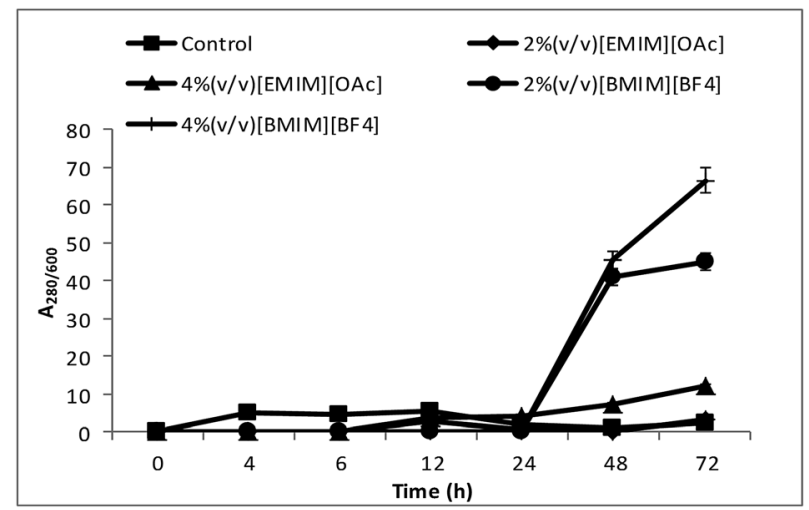

Fig. 4 Cell membrane permeability of $S$. thermophile in the presence of ILs. S. thermophile cells were grown in Emerson's medium in the absence (control) and presence of 2.0 and $4.0 \%(\mathrm{v} / \mathrm{v})$ compatible IL, [EMIM][OAc] and a non compatible IL, [BMIM] [BF 4 ]. Samples were withdrawn periodically and the release of nucleic acids and proteins during the growth of $S$. thermophile were estimated. The ratio of protein release with growth was plotted against different time intervals.

fungus appeared to be consisted of elongated hyphae containing conidia (Fig. 5a). The surface of the conidia appeared to be smooth and intact suggesting favourable growth conditions. In the presence of $2.0 \%(\mathrm{v} / \mathrm{v})$ [EMIM] [OAc], distinct mycelia were not observed and the conidia showed a wrinkled appearance with crevices like developments in the middle (Fig. 5b). This result is indicative of a partial dehydration of the cytoplasm which supports and is in agreement of the membrane permeability results (Fig. 4). The morphological features of the mycelium were observed to be severely disrupted in the presence of non-compatible IL, [BMIM] $\left[\mathrm{BF}_{4}\right]$ (Fig. 5c). The mechanism of the damaging effect of ILs may be correlated with that of organic solvents since ILs have been regarded as designer solvents due to their tunability and advantageous properties. ${ }^{41-43}$ Solvents are reported to damage the integrity of cellular membranes thereby causing changes in permeability. ${ }^{\mathbf{4 0 , 4 4}}$ The extreme shrinkage and shrivelled appearance of the cellular structure may possibly be due to the leakage of the intracellular components. The SEM images showed that the IL $[\mathrm{BMIM}]\left[\mathrm{BF}_{4}\right]$ is toxic and damaging to $S$. thermophile cells.

To further study the effect of ILs on the external morphology of $S$. thermophile spores, AFM was used to examine the same. Fig. 6 shows the morphology of the fungal spores in the presence of the contrasting ILs, [EMIM] [OAc] and [BMIM] $\left[\mathrm{BF}_{4}\right]$.

The images scanned at $10.0 \mu \mathrm{m}$ scan size showed a similar size and topography of the spores in the absence and presence of [EMIM][OAc] (Fig. 6a and b). On the other hand, the spores showed an irregular and clumped appearance in the presence of [BMIM] $]\left[\mathrm{BF}_{4}\right]$ (Fig. 6c).

To further elucidate the changes if any that might be occurring in the membrane of $S$. thermophile due to effect of ILs, TEM analysis was also carried out. In the control sample a clear intact membrane was observed (Fig. 7a). In the presence of $2.0 \%$ [EMIM][OAc] the cell membrane was found to be intact but some loss of definition in the cell structure was seen (Fig. 7b). 

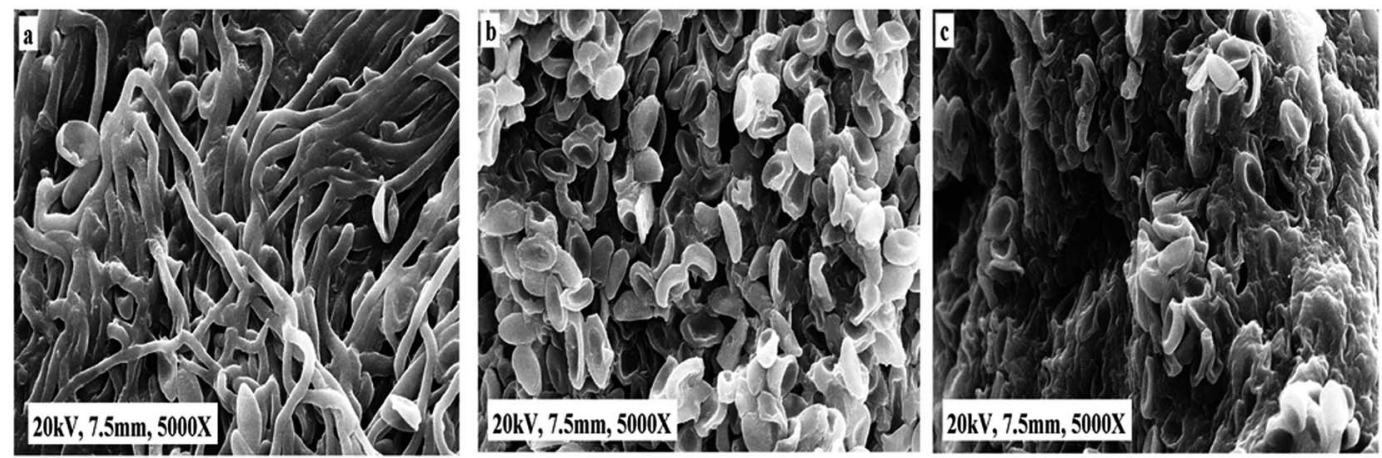

Fig. 5 SEM images of S. thermophile mycelial morphology in ILs presence. (a) Control (in the absence of ILs), (b) in the presence of $2.0 \%$ (v/v) [EMIM][OAC], (c)] in the presence of 2.0\% (v/v) [BMIM] [BF 4 ]. Magnification used: $5000 \times$

On the contrary, the cell membrane in the presence of $2.0 \%$ $[\mathrm{BMIM}]\left[\mathrm{BF}_{4}\right]$ was found to be damaged and destabilised (Fig. 7c). The appearance was that of a wrinkled and collapsed structure. The cytoplasm was also found to develop vacuoles. It is possible that the fatty acids present in the membrane might have been disrupted and led to the release of cytoplasmic contents in the extracellular medium. To probe further into the membrane fatty acid profile under ILs effect, FAME analysis was conducted in further studies.

\section{ILs effect on $S$. thermophile membrane lipid composition}

FAME analysis for the fatty acid profile of $S$. thermophile under ILs stress revealed some pertinent information about membrane adaptability under two different ILs systems, [EMIM] [OAc] and [BMIM] $\left[\mathrm{BF}_{4}\right]$ (Fig. 8).

(a) The control sample showed a higher composition of saturated fatty acids (SFA) whereas there was almost a $10.0 \%$ and $40.0 \%$ reduction in the presence of [EMIM] [OAc] and $[\mathrm{BMIM}]\left[\mathrm{BF}_{4}\right]$ respectively. Among the SFA, $\mathrm{C}_{16}, \mathrm{C}_{18}$ and $\mathrm{C}_{20}$ were the prominent ones present.

(b) An increase in the content of short chain (SCFA) and branched fatty acids (BFA) was seen along with a concomitant decrease in the long chain fatty acids (LCFA). In the BFA profile, the isoforms were observed to be getting converted to anteiso forms. Anteiso branched fatty acids are produced as a strategy to cope up under stress conditions..$^{45,46}$ The low melting point of these forms help in providing fluidity to the membrane.

(c) The unsaturated fatty acids (UFA) were observed to increase in the presence of both ILs. The increase was more in $[\mathrm{BMIM}]\left[\mathrm{BF}_{4}\right]$ indicating that this particular IL caused major stress in the membrane.

The studies conducted on the alteration of lipid composition of the microbial membrane under ILs effect are very scarce. A recent report conducted on algal membrane as the model system found that the cation portion of the ILs gets inserted into the lipid bilayer and tend to distort or bend the membrane to maximise the surface area for the hydrophobic interaction with the ILs. ${ }^{47}$ The anions moiety of the ILs on the other hand have also been reported to get inserted in the lipid bilayer. ${ }^{48}$ The morphological effects of such phenomenon is the alteration in cell membrane permeability as well as its cellular functions. ${ }^{19}$ In a similar study, ILs have been shown to disrupt the ion channels in the membrane thereby disturbing the homeostasis. ${ }^{49}$ Since ILs are solvents, we have tried to correlate our findings with the existing reports on the response of various microorganisms to solvent stress. The strategy to cope with solvent stress is usually done by either increasing double bonds or by shortening the length of the fatty acyl chain. ${ }^{45,50}$ In many microbial species, a transition of the membrane from the lamellar to the hexagonal state has also been observed. ${ }^{51,52}$ Zhang and Rock, $(2008)^{53}$ proposed
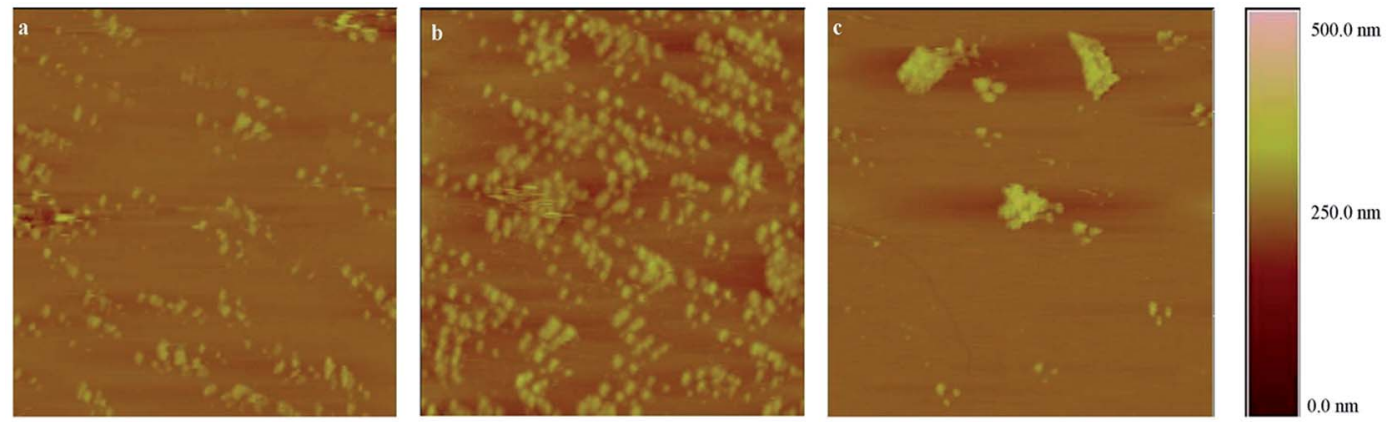

Fig. 6 AFM images showing topographical structure of $S$. thermophile spores in ILs presence. (a) Control (in the absence of ILs), (b) in the presence of 2.0\% [EMIM][OAc], (c) in the presence of 2.0\% (v/v) [BMIM][BF 4 . 

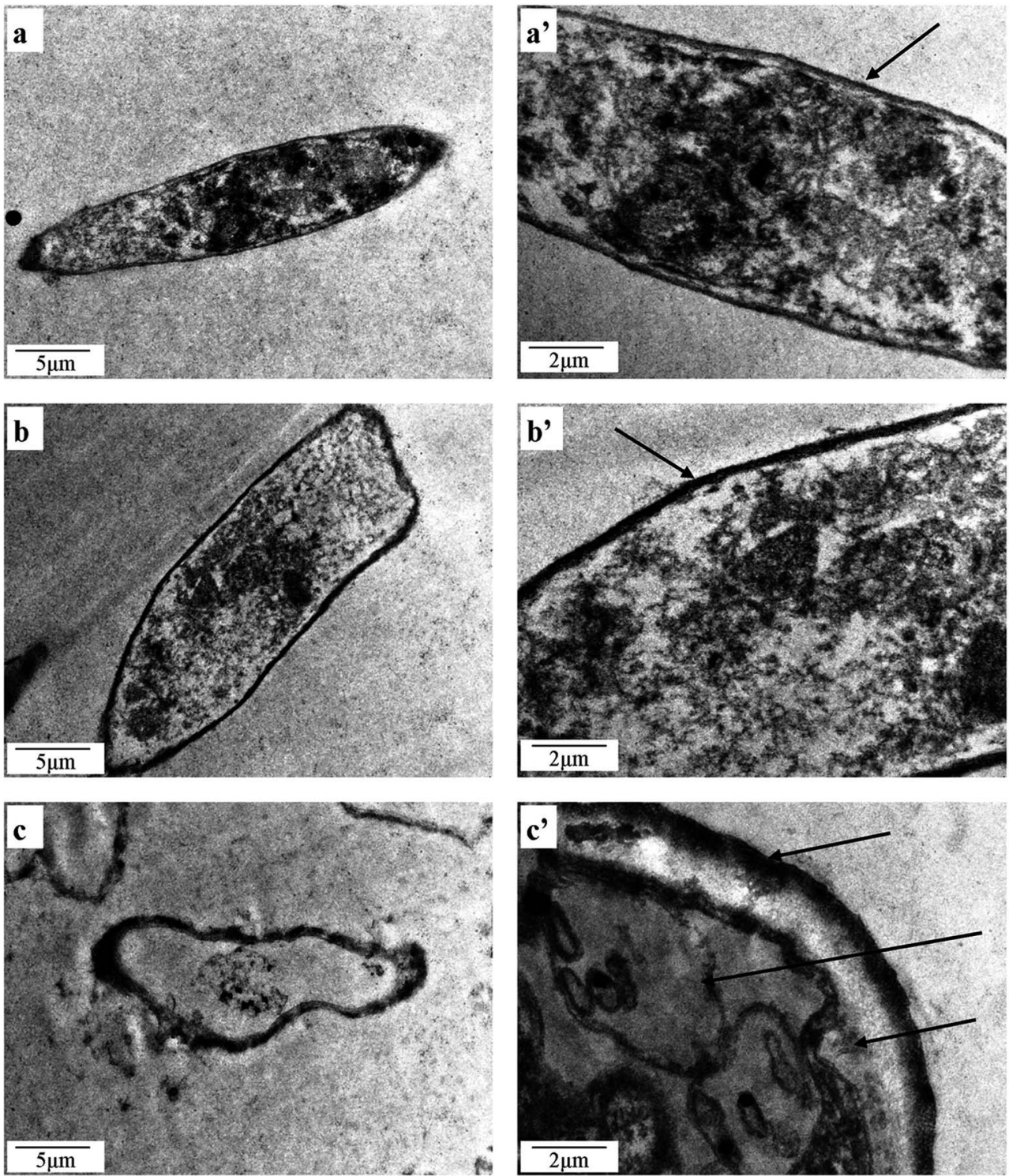

Fig. 7 TEM images showing S. thermophile changes in membrane and cytoplasm in ILs presence control (in the absence of ILs) (a) $5 \mu \mathrm{m}$ ( $\mathrm{a}^{\prime}$ ) $2 \mu \mathrm{m}$, in the presence of $2.0 \%(\mathrm{v} / \mathrm{v})$ [EMIM][OAc] (b) $5 \mu \mathrm{m}\left(\mathrm{b}^{\prime}\right) 2 \mu \mathrm{m}$, in the presence of $2.0 \%(\mathrm{v} / \mathrm{v})$ [BMIM][BF 4 (c) $5 \mu \mathrm{m}$ (c') $2 \mu \mathrm{m}$.

that the membrane adjusts to the solvent stress by inducing expression of specific genes coding for the enzymes like phospholipid acyl-chain desaturases and phospholipid cistrans isomerases which are involved in the modification of the existing phospholipid chains. Hence the various changes proposed above provide a cumulative mechanism of the microbial membranes to optimise their functioning under stress conditions.

\section{Application of ILs adapted S. thermophile in whole cell biocatalysis}

A study was conducted to check the amount of total reducing sugars generated by the saccharification of [EMIM][OAc] pretreated wheat straw using IL adapted $S$. thermophile cells containing xylanase activity. Briefly wheat straw was pre-treated with [EMIM] [OAc] at $33.0 \%(\mathrm{w} / \mathrm{w})$ biomass loading at $120{ }^{\circ} \mathrm{C}$ for $3 \mathrm{~h}$. Post pre-treatment, $S$. thermophile cells containing 25.0 $\mathrm{U} \mathrm{mL} L^{-1}$ xylanase activity were added and hydrolysis reaction was performed till $48 \mathrm{~h}$ at $40^{\circ} \mathrm{C}$. Three types of control reactions were also run simultaneously.

In the first control, instead of [EMIM][OAc], $0.05 \mathrm{M}$ sodium phosphate buffer $\mathrm{pH} 7.0$ was used for wheat straw pre-treatment followed by hydrolysis utilizing $S$. thermophile adapted cells.

In the second control, [EMIM][OAc] was used for wheat straw pre-treatment under the above described conditions followed by hydrolysis in the absence of $S$. thermophile cells.

In the third control type, [EMIM][OAc] was used for wheat straw pre-treatment followed by hydrolysis in the presence of non-adapted $S$. thermophile cells.

The results of the study conducted gave promising results suggesting that the adapted $S$. thermophile cells can be used for 


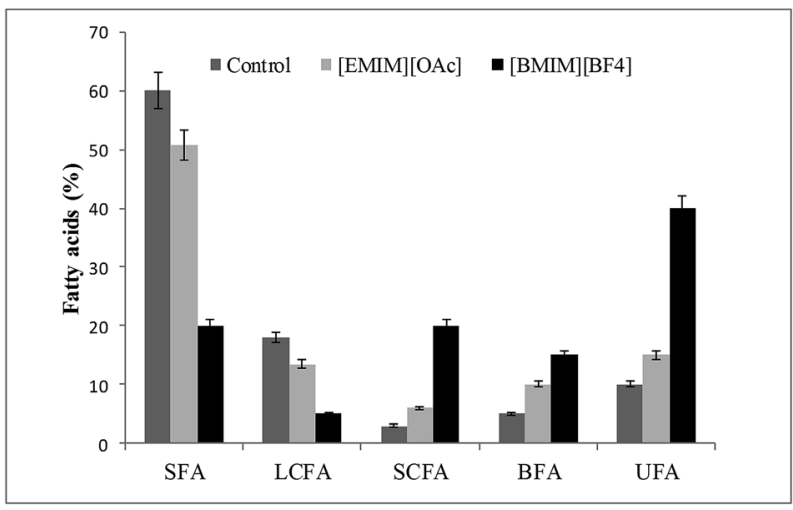

Fig. 8 Fatty acid composition of S. thermophile in the presence of ILs. S. thermophile grown in the presence and absence of ILs at $2.0 \%(\mathrm{v} / \mathrm{v})$ concentration was harvested and the sample was processed for FAME analysis. SFA $=$ Saturated Fatty Acids, LCFA = Long Chain Fatty Acids, SCFA $=$ Short Chain Fatty Acids, BFA $=$ Branched Chain Fatty Acids, UFA $=$ Unsaturated Fatty Acid.

whole cell biocatalysis process using simultaneous pretreatment and hydrolysis approach. The results in Fig. 9 show the reducing sugars $\left(16.0 \mathrm{mg} \mathrm{mL}^{-1}\right)$ produced by adapted cells of $S$. thermophile. In the control samples (i-iii) relatively low amount of reducing sugars $\left(4.5 \mathrm{mg} \mathrm{mL}^{-1}, 1.3 \mathrm{mg} \mathrm{mL}^{-1}\right.$ and $10 \mathrm{mg} \mathrm{mL}{ }^{-1}$ respectively) were generated indicating the efficiency of IL pre-treatment as well as the adaptability mechanism of $S$. thermophile to [EMIM][OAc] leading to in situ pretreatment and saccharification.

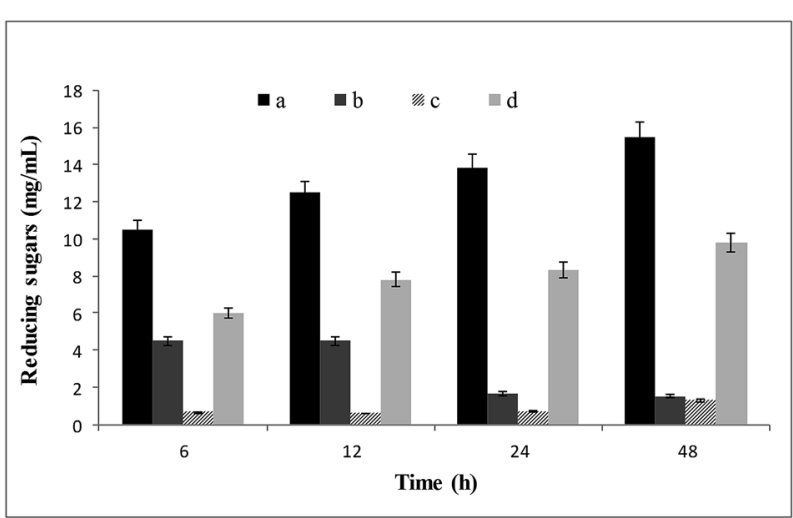

Fig. 9 Applicability of [EMIM][OAc] adapted S. thermophile whole cells in the in situ saccharification of [EMIM][OAc] pre-treated wheat straw. The culture of $S$. thermophile previously adapted in $1 \%(\mathrm{v} / \mathrm{v})$ [EMIM] [OAc] was further grown in the presence of $4.0 \%(\mathrm{v} / \mathrm{v}) \mathrm{IL}$ and the mycelium was harvested at the log phase of growth. The resultant adapted culture contained xylanase activity of $25 \mathrm{U} \mathrm{mL}^{-1}$. The nonadapted culture (not exposed to any ILs) also harvested at its log phase contained xylanase activity of $55 \mathrm{U} \mathrm{mL}^{-1}$. Wheat straw $(0.5 \mathrm{~g})$ was pretreated with (a) [EMIM][OAc] $(1.0 \mathrm{~mL})$ for $3.0 \mathrm{~h}$ at $120^{\circ} \mathrm{C}$ followed by addition of adapted cell extract for $48 \mathrm{~h}$ at $40^{\circ} \mathrm{C}$ (b) $0.05 \mathrm{M}$ sodium phosphate buffer, $\mathrm{pH} 7.0(1 \mathrm{~mL})$ for $3 \mathrm{~h}$ at $120^{\circ} \mathrm{C}$ followed by addition of adapted cell extract for $48 \mathrm{~h}$ at $40^{\circ} \mathrm{C}$ (c) [EMIM] [OAc] $(1.0 \mathrm{~mL})$ for $3 \mathrm{~h}$ at $120^{\circ} \mathrm{C}$ in the absence of any adapted cell extract for $48 \mathrm{~h}$ at $40^{\circ} \mathrm{C}$ (d) [EMIM][OAC] $(1.0 \mathrm{~mL})$ for $3 \mathrm{~h}$ at $120^{\circ} \mathrm{C}$ with addition of non-adapted cell extract for $48 \mathrm{~h}$ at $40{ }^{\circ} \mathrm{C}$.

\section{Conclusions}

The S. thermophile strain was initially screened for growth and xylanase production in hydrophilic imidazolium based ILs. It was found to tolerate [EMIM][OAc], [BMIM] $\left[\mathrm{MeSO}_{4}\right]$ and [BMIM] [Otf] while being inhibited by $[\mathrm{BMIM}]\left[\mathrm{BF}_{4}\right]$ and $[\mathrm{HMIM}]\left[\mathrm{BF}_{4}\right]$. The tolerance of this particular strain in the compatible ILs was further enhanced by adapting its cells first at lower concentration of the respective ILs and then increasing the concentration successively. The adapted $S$. thermophile strain could grow and produce comparable xylanase activity in the presence of $4.0 \%(\mathrm{v} /$ v) [EMIM] [OAc]. The advantage of [EMIM][OAc] adaptation in $S$. thermophile was extended to explore its ability to perform whole cell biocatalysis in the in situ saccharification of IL pre-treated wheat straw. This approach would reduce the overall cost of biofuel production keeping in mind the high cost of enzymes and IL systems.

\section{Acknowledgements}

The authors are grateful to Prof. T. Satyanarayana, Department of Microbiology, Delhi University South Campus, New Delhi for providing the S. thermophile culture for this study. The authors acknowledge Prof. M. N. Gupta, Emeritus, Department of Biochemical Engineering and Biotechnology, IIT Delhi for proof reading and providing key inputs in the revised manuscript. The financial assistance provided to AS by the Ministry of Human Resource and Development and IIT Delhi is gratefully appreciated.

\section{References}

1 S. Raposo, A. Constantino, F. Rodrigues, B. Rodrigues and M. E. Lima-Costa, Appl. Biochem. Biotechnol., 2016, 181, 827-843.

2 J. M. E. Storey, M. P. Bunce, E. M. Clarke, J. W. Edmonds, R. H. Findlay, S. M. C. Ritchie, L. Eyers, Z. A. McMurry and J. C. Smoot, Environ. Sci. Pollut. Res., 2016, 23, 18575-18584.

3 A. Brandt, J. Gräsvik, J. P. Hallett and T. Welton, Green Chem., 2013, 15, 550-583.

4 S. K. Khare, A. Pandey and C. Larroche, Biochem. Eng. J., 2015, 102, 38-44.

5 L. Capolupo and V. Faraco, Appl. Microbiol. Biotechnol., 2016, 1-17.

6 F. J. Gschwend, A. Brandt, C. L. Chambon, W. C. Tu, L. Weigand and J. P. Hallett, J. Visualized Exp., 2016, DOI: 10.3791/54246.

7 S. Zhu, Y. Wu, Q. Chen, Z. Yu, C. Wang, S. Jin, Y. Ding and G. Wu, Green Chem., 2006, 8, 325-327.

8 R. A. Sheldon, Chem.-Eur. J., 2016, 22, 12984-12999.

9 X. D. Hou, T. J. Smith, N. Li and M. H. Zong, Biotechnol. Bioeng., 2012, 109, 2484-2493.

10 J. Sperry and J. Garcia-Alvarez, Molecules, 2016, 21, 1-3.

11 R. D. Rogers and K. R. Seddon, Science, 2003, 302, 792-793.

12 A. M. Socha, R. Parthasarathi, J. Shi, S. Pattathil, D. Whyte, M. Bergeron, A. George, K. Tran, V. Stavila and 
S. Venkatachalam, Proc. Natl. Acad. Sci. U. S. A., 2014, 111, E3587-E3595.

13 M. Ouellet, S. Datta, D. C. Dibble, P. R. Tamrakar, P. I. Benke, C. Li, S. Singh, K. L. Sale, P. D. Adams and J. D. Keasling, Green Chem., 2011, 13, 2743-2749.

14 A. Romero, A. Santos, J. Tojo and A. Rodriguez, J. Hazard. Mater., 2008, 151, 268-273.

15 J. M. Gladden, J. I. Park, J. Bergmann, V. Reyes-Ortiz, P. D’haeseleer, B. F. Quirino, K. L. Sale, B. A. Simmons and S. W. Singer, Biotechnol. Biofuels, 2014, 7, 1.

16 J. Xu, X. Wang, L. Hu, J. Xia, Z. Wu, N. Xu, B. Dai and B. Wu, Bioresour. Technol., 2015, 181, 18-25.

17 V. Tsarpali and S. Dailianis, Ecotoxicol. Environ. Saf., 2015, 117, 62-71.

18 N. Mehmood, E. Husson, C. Jacquard, S. Wewetzer, J. Büchs, C. Sarazin and I. Gosselin, Biotechnol. Biofuels, 2015, 8, 1-13.

19 Y. Shen, L. Wang, J. Liang, R. Tang and M. Wang, Microb. Cell Fact., 2016, 15, 1-10.

20 A. Sadaf, V. K. Morya and S. Khare, Process Biochem., 2016, 51, 2090-2096.

21 G. L. Miller, Anal. Chem., 1959, 31, 426-428.

22 F. M. Freimoser, C. A. Jakob, M. Aebi and U. Tuor, Appl. Environ. Microbiol., 1999, 65, 3727-3729.

23 V. K. Gupta, M. G. Tuohy, M. Ayyachamy, K. M. Turner and A. O'Donovan, Laboratory Protocols in Fungal Biology, Springer Science \& Business Media, 2012.

24 G. David, J. Herbert and G. Wright, J. Anat., 1973, 115, 79-97.

25 T. A. Voelker and H. M. Davies, J. Bacteriol., 1994, 176, 73207327.

26 H. Zhao, J. Chem. Technol. Biotechnol., 2016, 91, 25-50.

27 F. Ganske and U. T. Bornscheuer, Biotechnol. Lett., 2006, 28, 465-469.

28 N. Gathergood, M. T. Garcia and P. J. Scammells, Green Chem., 2004, 6, 166-175.

$29 \mathrm{~W}$. L. Hough-Troutman, M. Smiglak, S. Griffin, W. M. Reichert, I. Mirska, J. Jodynis-Liebert, T. Adamska, J. Nawrot, M. Stasiewicz and R. D. Rogers, New J. Chem., 2009, 33, 26-33.

30 P. C. Pinto, S. P. Costa, J. L. Lima and M. L. M. Saraiva, Ecotoxicol. Environ. Saf., 2012, 80, 97-102.

31 S. P. Costa, P. C. Pinto, R. A. Lapa and M. L. M. Saraiva, J. Hazard. Mater., 2015, 284, 136-142.

32 H. Zhao, J. Mol. Catal. B: Enzym., 2005, 37, 16-25.
33 H. Zhao, J. Chem. Technol. Biotechnol., 2006, 81, 877-891.

34 M. Montalbán, M. Collado-González, R. Trigo, F. Díaz Baños and G. Víllora, J. Adv. Chem. Eng., 2015, 5, 1-9.

35 F. J. Weber, L. P. Ooijkaas, R. Schemen, S. Hartmans and J. De Bont, Appl. Environ. Microbiol., 1993, 59, 3502-3504.

36 J. A. Imlay, Nat. Rev. Microbiol., 2013, 11, 443-454.

37 J. Viell, H. Inouye, N. K. Szekely, H. Frielinghaus, C. Marks, Y. Wang, N. Anders, A. C. Spiess and L. Makowski, Biotechnol. Biofuels, 2016, 9, 1-15.

38 N. Gal, D. Malferarri, S. Kolusheva, P. Galletti, E. Tagliavini and R. Jelinek, Biochim. Biophys. Acta, Biomembr., 2012, 1818, 2967-2974.

39 S. K. Mikkola, A. Robciuc, J. Lokajova, A. J. Holding, M. Lämmerhofer, I. Kilpeläinen, J. M. Holopainen, A. W. King and S. K. Wiedmer, Environ. Sci. Technol., 2015, 49, 1870-1878.

40 M. Yang, H. Wu, Y. Lian, X. Li, F. Lai and G. Zhao, PLoS One, 2014, 9, e104847.

41 M. Freemantle, Chem. Eng. News, 1998, 76, 32-37.

42 M. Freemantle, Chem. Eng. News, 2004, 82, 10.

43 I. Newington, J. M. Perez-Arlandis and T. Welton, Org. Lett., 2007, 9, 5247-5250.

44 S. A. Nicolaou, S. M. Gaida and E. T. Papoutsakis, Metab. Eng., 2010, 12, 307-331.

45 L. E. Nielsen, D. R. Kadavy, S. Rajagopal, R. Drijber and K. W. Nickerson, Appl. Environ. Microbiol., 2005, 71, 51715176.

46 M. Unell, N. Kabelitz, J. K. Jansson and H. J. Heipieper, FEMS Microbiol. Lett., 2007, 266, 138-143.

47 B. Yoo, B. Jing, S. E. Jones, G. A. Lamberti, Y. Zhu, J. K. Shah and E. J. Maginn, Sci. Rep., 2016, 6, 1-7.

48 B. Yoo, J. K. Shah, Y. Zhu and E. J. Maginn, Soft Matter, 2014, 10, 8641-8651.

49 H. Ryu, H. Lee, S. Iwata, S. Choi, M. K. Kim, Y. R. Kim, S. Maruta, S. M. Kim and T. J. Jeon, Sci. Rep., 2015, 5, 1-11.

50 L. Beney and P. Gervais, Appl. Microbiol. Biotechnol., 2001, 57, 34-42.

51 G. Van Meer, D. R. Voelker and G. W. Feigenson, Nat. Rev. Mol. Cell Biol., 2008, 9, 112-124.

52 R. Koynova and B. Tenchov, OA Biochem., 2013, 1, 1-9.

53 Y.-M. Zhang and C. O. Rock, Nat. Rev. Microbiol., 2008, 6, 222-233. 